العلاقة بين معدل التضخم ومعدل البطالة في مناطق السلطة الوطنية الفلسطينية

$$
\text { دراسة قياسية للفترة (1997- 2019م) }
$$

The relationship between the inflation rate and the unemployment rate in the areas of the Palestinian National Authority Standard Study for the period (2019-1997)

جلال نافل شيخ العيد

Jalal N. S. Sheikhalid

1قسم العلوم الإدارية والمالية, الكلية الجامعية للعلوم والتكنولوجيا, خانيونس , قطاع غزة, فلسطين

${ }^{1}$ Department of Administrative and Financial Sciences, University College of Sciences and Technology, Khan Younis, Gaza Strip, Palestine

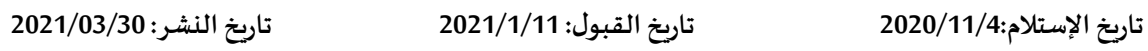

المستخلص: تناولت الدراسـة مشكلتي: البطالة, والتضخم في مناطق السلطة الوطنية, ومن ثم تناولتها على مستوى الضفة الغربية, وقطاع غزة كل على حدة خلال الفترة الزمنية (1997-2019م).هدفت الدراسة إلى إظهار مدى قوة الارتباط بين البطالة والتضخم في الاقتصاد الفلسطيني ككل, وفي اقتصادي الضفة الغربية, وقطاع غزة كل على على حدة.

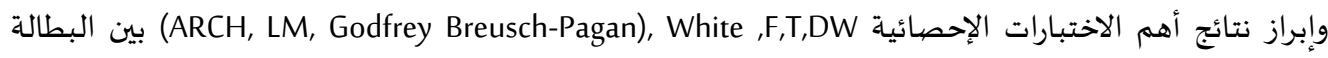
والتضخم في الاقتصاد الفلسطيني ككل, وفي اقتصادي الضفة الغربية, وقطاع غزة كل على حدة. وقياس الأثر المفاجئ

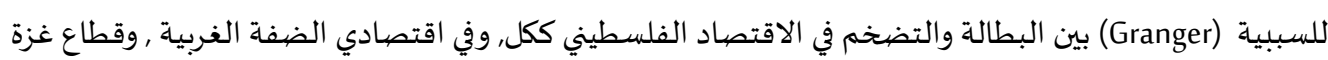
كل على حدة ـ وتوصلت الدراسة إلى إمكانية تطبيق منحنى فيليبس على الاقتصاد الفلسطيني عامة، وبشقياء: الضفة

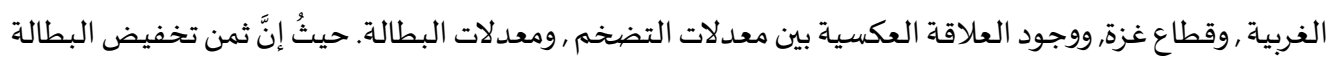
حدوث ارتفاع شديد في معدلات التضخم. تعتبر حالة التضخم في الاقتصاد الفلسطيني عامة، وبشقيه: الضفة الغرونة الغربية, وقطاع غزة قائمة على أساس تفوق الطلب الكلي (AD) على العرض الكلي(AS) للسلع والخدمات التي يحتاجها أفراد المجتمع الفلسطيني. الكلمات المفتاحية: البطالة, التضخم, منحنى فيليبس, توظيف.

Abstract : This study discusses the problems of both unemployment and inflation in the areas of the Palestinian National Authority, compare with the West Bank and the Gaza Strip separately, during the period (1997-2019). This study aims to show the strength of connection between unemployment and inflation in whole Palestinian economy, and the economy of both the West Bank and Gaza Strip, separately, highlighting the results of the most important statistical tests (F, T, DW, ARCH, LM, Godfrey Breusch- Pagan, White) between unemployment and inflation in the Palestinian economy as one unit, compared to the economies of the West Bank and Gaza Strip separately. This study measuring the surprising effect of the "Granger" causality between unemployment and inflation on the Palestinian economy as one unit; compare to the economies of the West Bank and Gaza Strip separately. The study found the possibility of applying the Phillips curve to the Palestinian economy in general, and both parts

jalal68sallam@gmail.com ايميل الباحث الرئيسي: 
of the West Bank and Gaza Strip, and the existence of the inverse relationship between inflation rates and unemployment rates. The cost of reducing unemployment is a very high inflation rate. The inflation situation in the Palestinian economy in general, and in both parts of the West Bank and Gaza Strip, is based on the superiority of aggregate demand (AD) over the overall supply (AS) of goods and services needed by members of the Palestinian community.

Keywords: Unemployment, inflation, Phillips curve, employment.

يعاني الاقتصاد الفلسطيني من اختلالات هيكلية بالغة الخطورة سببتها سبعة عقود من الاحتلال للأراضي الفلسطينية. ومن مظاهرها ضعف القدرة الاستيعابية للاقتصاد الفلسطيني للقوى العاملة, واعتماده الكبير على الأسواق الخارجية؛ لخلق فرص العمل التي تراجعت بشكل حاد في السنوات العشـر الأخيرة؛ مما أدى إلى فقدان القوى العاملة الفلسطينية لفرص العمل المتاحة في الأسواق الخارجية, وزاد من تضخم البطالة في مناطق السلطة الوطنية الفلسطينية.

ويعتبر موضوع البطالة, والتضخم من الموضوعات التي حظيت بالاهتمام والبحث في كافة الدول لاسيما المتقدمة, حيثُ

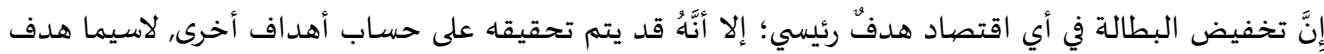
استقرار المستوى العام للأسعار. وتعددت النظريات الاقتصادية التي فسرت هاتين الظاهرتين, وعلاقتهما بعضهما ببعض, وقد شجعت دراسة فيليبس التي أظهرت وجود علاقة عكسية بين البطالة, والتضخم في الستينات الكثير من

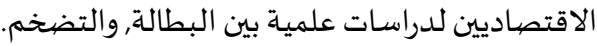

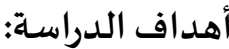

تهدف إلى رسم السياسـات الاقتصادية لصناع القرار الفلسطيني, والمساعدة في وضع خطط التنمية الاقتصادية من خلال: 1. توضيح الإطار النظري للعلاقة بين البطالة, والتضخم وفق منحنى فيليبس. 2. تقدير منحنى فيليبس في الاقتصاد الفلسطيني, واختبار مدى مطابقته لواقع الاقتصاد الفلسطيني ككل, وعلى الفي

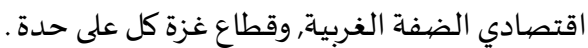

3. إبراز نوعية العلاقة بين البطالة, والتضخم في الاقتصاد الفلسطيني ككل, وفي اقتصادي الضفة الغربية, وقطاع غزة كل على حدة. 4. 4 - إظهار مدى قوة الارتباط بين البطالة, والتضخم في الاقتصاد الفلسطيني ككل, وفي اقتصادي الضفة الغربية , وقطاع غزة كل على حدة .

5. قياس الأثر المفاجئ للسببية (Granger) بين البطالة,والتضخم في الاقتصاد الفلسطيني ككل,وفي اقتصادي الضفة

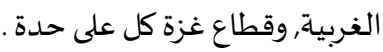

\section{مشـكلة الدراسـة:}

يعاني الاقتصاد الفلسطيني من وجود معدلات مرتفعة من البطالة, والتضخم, وما نتج عنهما من آثار اقتصادية,

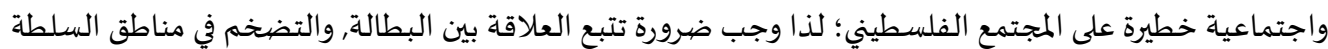
الوطنية الفلسطينية للفترة (2019/1997م) عبر دراسة قياسية باستخدام برنامج (Eviewes10)؛ لتقدير العلاقة بين

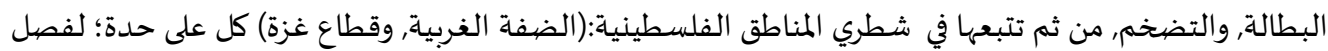
الاحتلال الإسرائيلي بينهما جغرافياً, 
وحدوث انقسام فلسطيني, وتمركز القرار الفلسطيني المركزي في الضفة الغربية, فيما تسيطر حركة حماس على قطاع غزة منذ منتصف عام 2007م.

تساؤلات الدراسـة:

مشكلة التضخم ليست المشكلة الوحيدة التي يعاني منها الاقتصاد الفلسطيني بل رافقت معه حالة من الركود الاقتصادي, وانخفاض معدلات التوظيف, والنمو الاقتصادي. وفي هذه الدراسة نحاول الإجابة عن السؤال الرئيس

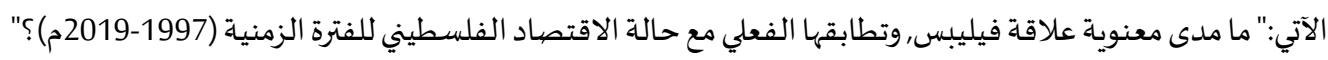
ويتفرع عن السؤال مجموعة الأسئلة الفرعية الآتية: 1. هل علاقة فيليبس بين البطالة, والتضخم محققة في الاقتصاد الفلسطيني ككل خلال فترة الدراسة وفي اقتصادي

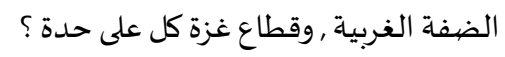
2. ما هي قوة الارتباط بين البطالة, والتضخم في الاقتصاد الفلسطيني ككل, وفي اقتصادي الضفة الغربية,ووقطاع غزة كل على حدة ؟ مالى 3. ما مدى تطابق المؤشرات الإحصائية التي تقيس العلاقة البطالة, والتضخم في الاقتصاد الفلسطيني ككل, وفي

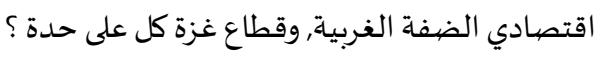
4. هل يوجد أثر متبادل بين متغير التضخم, وبين متغير البطالة في الاقتصاد الفلسطيني ككل, وفي اقتصادي الضيفة

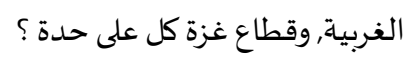

أهمية الدراسـة:

يُعدُّ موضيوع البطالة, والتضخم من الموضوعات التي تهم صناع القرار الاقتصيادي الفلسطيني في اتخاذ القرار السليم

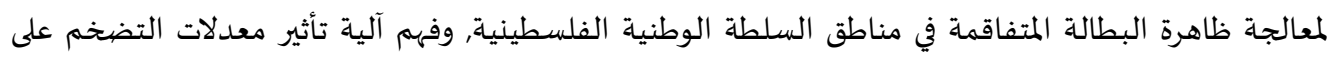

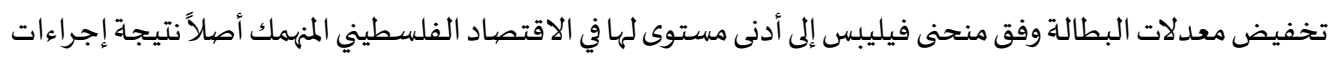

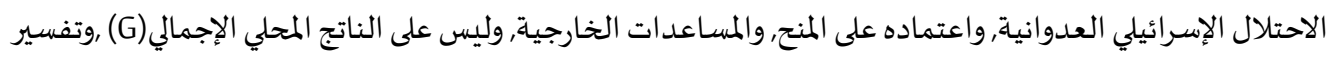

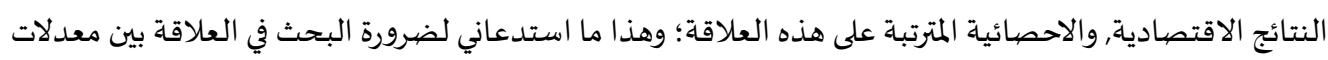
البطالة, والتضخم في مناطق السلطة الوطنية الفلسطينية.

حدود الدراسـة: (إحة الحد الموضوعي: اقتصرت الدراسـة في حده الموضوعي على العلاقة بين البطالة, والتضخم.

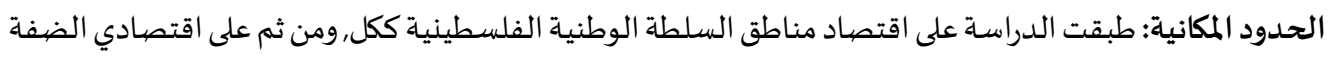

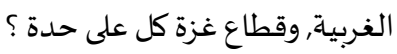
الحدود الزمنية: اعتمدت الدراسة على سلسلة زمنية لظاهرتي: البطالة والتضخم للفترة(2019/1997م).

\section{مصطلحات الدراسة:}

التضخم (Inflation): هو ارتفاع المعدل العام للأسعار خلال فترة من الزمن, والتي تكون عادة سنة واحدة أو أكثر.)

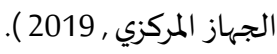
البطالة(unemployment):"جميع الافراد الذين ينتمون لسن العمل (15 فأكثر), ولم يعملوا أبداً خلال فترة الإسناد في أي نوع من الأعمال, وكانوا خلال هذه الفترة مستعدين للعمل, وقاموا بالبحث عنه بإحدى الوسائل المتاحة"(الجهاز المركزي , 2019). 
الركود التضخمي (Stagflation): هو الارتفاع المستمر في المستوى العام للأسعار المرافق للبطالة المتزايدة, وانخفاض مستويات الناتج القومي, ومعدلات نموه خلال فترة زمنية معينة" (زكي , 1986). الدراسـات السـابقة للدراسـة:

1- (2014) (2014):

هدفت الدراسة إلى تقدير معادلة منحنى فيليبس باستخدام بيانات حول البطالة والتضخم في العراق للفترة (19912011م). وتوصلت إلى وجود علاقة عكسية بين معدل البطالة ومعدل التضخم للفترة (1991-2002)؛ حيثُ إنَّ زيادة في معدل التضخم بنقطة واحدة سيؤدي لانخفاض البطالة بمقدار (0.0047) نقطة في المتوسط, وإِنَّ مرونة البطالة للتضخم (-0.035).أما الفترة (2003-2011) فوجدت العلاقة بينهما طردياة, وظهور الركود التضخمي؛ بسبب مساهمة

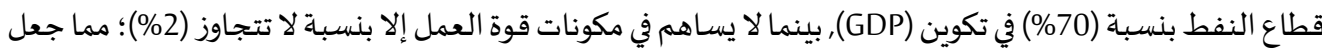
الاقتصاد العراقي خدمي.

2- دراسة ميلود واخرون (2018):

هدفت الدراسة إلى دراسة العلاقة بين البطالة والتضخم في الجزائر للفترة (2000-2015) دراسة قياسية, وتوصهلت

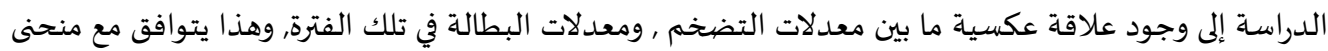

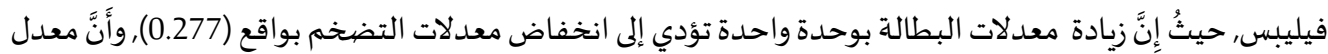
التحديد المعدل (24\%) وهو ضيعيف جداً؛ وفسرت الدراسة وجود أسباب أخرى تؤثر على التضخم في البطالة منها الكتلة النقدية, وعجز الموازنة المستمر ,والتضخم المستورد ,وتآكل قيمة الدينار الجزائري.

: Umoru and Anyiwe (2013).

هدفت الدراسة الى اختبار ديناميكيات البطالة والتضخم في دولة نيجيريا باستخدام نموذج تصحيح الخطأ لفترة 27

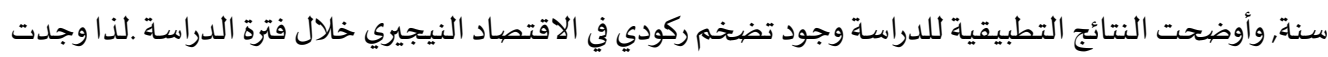
علاقة طردية بين معدلات البطالة و معدلات التضخم منذ سنة 1986 رمما يبطل فرضية منحنى فيلبس للعلاقة بين البطالة والتضخم في نيجيريا. و توصلت الدراسـة الى العوامل المحتملة المسببة للتضخم الركودي في نيجيريا المتمثلة في تبني استهداف التضخم مما يسهل التوقعات التضخمية, و تواجد فائض كبير في اليد العاملة في البلد مما يؤدي إلى لي جمود في سوق العمل وهيكل الأجور في الاقتصاد النيجيري. قدمت الدراسة لمواجهة هذه الظاهرة عدة توصيات تمثلت في :العمل على زيادة الناتج المحلي الإجمالي أكثر من عرض

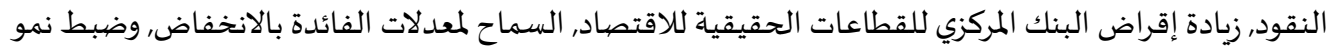
النقود من أجل دفع النمو الاقتصيادي, وأيضيا على الحكومة خلق صناعات تحويلية خاصة وأن 70 \%من قوة عمل البلد يعملون في الزراعة كنشاط اقتصادي رئيسي لسكان نيجيريا.

4- دراسة (2014 ) Fumitaka \& Munir

هدفت الدراسـة إلى التحليل القياسي للعلاقة بين معدل البطالة, ومعدل التضخم في الدولة النامية بصففة عامة وماليزيا بصفة خاصةة, وقد توصلت الدراسة إلى وجود علاقة عكسية بين معدل البطالة ومعدل التضخم في ماليزيا, وبالتالي؛

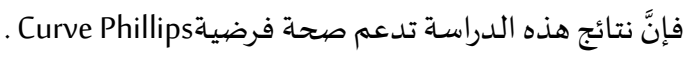


: Sargent (1978) : دراسـ

تناولت الدراسة اختبار العلاقة العكسية بين التضخم والبطالة في الاقتصاد الأمريكي, وتوصلت الدراسة إلى أنَّ أثر

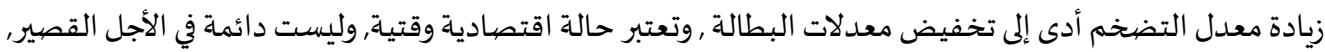

ومستقلة تماماً في الأجل الطويل.

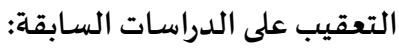

اتفقت الدراسة الحالية مع الدراسات السابقة على توضيح العلاقة بين البطالة والتضخم لسلسلة زمنية, ومن ثم مقارنة نتائج هذه الدراسات بفرضية Curve Phillips , التي أظهرت وجود علاقة عكسية بين معدلات البطالة ,ومعدلات

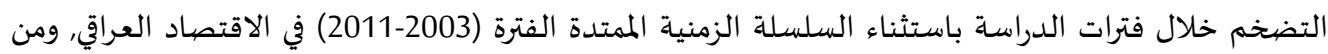
OCDE حيثُ أوجدت العلاقة ظاهرة الركود التضخمي كما وجدت, واتفقت الدراسـة مع الدراسات السابقة في طرق قياس هذه العلاقة بينما استرشـت الدراسـة الحالية ببعض الدراسـات السابقة التي تناولت نموذج الانحدار الخطي البسيط, وإجراء الاختبارات الملائمسة, إلا أنَّ هذه الدراسة تختلف عن الدراسات السابقة في مجال التطبيق, حيثُ تم تطبيق الدراسة الحالية على الاقتصاد الفلسطيني خلال

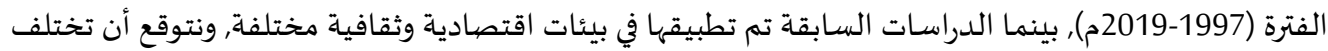
النتائج عند اختبار الفرضيات في الدراسة الحالية والتي تم اختبارها في بيئة اقتصادية مختلفة،, وفي فترة زمنية مختلفة.

\section{الإطار النظري للدراسة:}

أ. الخلفية التاريخية للعلاقة بين البطالة والتضخم :

لقد كان أول من تطرق إلى هذه العلاقة بشكل واضح المفكر النيوكلاسكي Fischer Irving سنة 1926, حيثُ بيّن أَنَّ هناك معضلةParadoxe , تتلخص أنَّ العوامل التي تسهم في زيادة معدلات التضخمه رمثل: العجز المتراكم, وتزايد الكمية

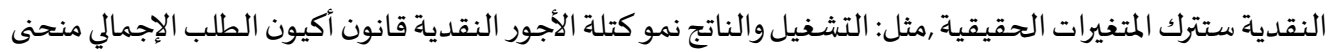
فيلبس نمو(RGDP( دون أي تأثير. ولا شك بأَنَّ عدم انتشار الفكرة في بداية الأمر كانت مناقضية للتحليل الكلاسيكي السائد آنذاك, ( معروف , 2005)

كانت عدة محاولات عام 1936 من طرف Timbergen, كذلك في عام 195 كانت محاولة من قبل Klein ,ومن ثم تم

رسم Brown سنة Sultan وسنة 1957 هذه هذه العلاقة في شكل انتشاري, وبياني , ورغم هذه الجهود المتطورة آنذاك إلأَنَّ ظهور التحليل الحقيقي بدأ مع الاقتصادي النيوزلندي " A.W. Philips " سنة 1958.

1 Philips Curve التحليل الوصفي لمنتحنى

قام فيلبس في سنة 1958م بنشر دراسة مصممة في مجلة (Economics,issue135) حول العلاقة التاريخية التي تربط

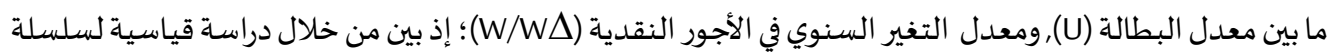
إحصائية أجراها على الاقتصاد الإنجليزي( المملكة المتحدة) للفترة الممتدة (1957-1861) وجود علاقة تربط بين هذين

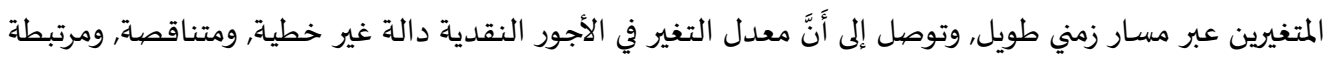
عكسياً مع معدل البطالة. طور هذا المنحنى حتى أصبح يستخدم في فئ رسم السياسات الاقتصادية للدولة) (Phillips,1958).

يرتكز نموذج فيليبس على الفرضيات الكينزية, التي افترضت التوظيف الكامل لعناصر الإنتاج في الاقتصاد الوطني, وكذلك إمكانيات التعديل بين العرض,والطلب بواسطة الكميات عوضياً عن فرضية الأسعار المرنة التي تفترضها مدرسية

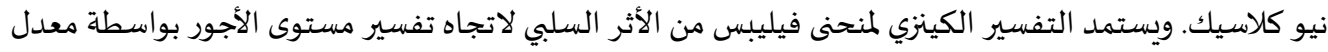


البطالة؛ حيثُ إنَّ الزيادة المضطردة في نمو الأجور الاسمية تؤدي إلى ارتفاع التكاليف الإنتاجية, التي تؤدي إلى تسريح العمال, ومن ثم ازدياد معدلات البطالة(موسوي, 2001 ).

أصبح منحنى فليبس أهم الأدوات المستخدمة في النظرية الكينزية؛ لأَنَّ ارتفاع معدلات البطالة ترتبط في زيادة الطلب الفعلي لما يتجاوز العرض المحقق من السلع و الخدمات في التوظيف الكامل كعناصر الإنتاج ,و يستدعي ذلك وجود معدلات البطالة إلى أدنى معدل سنوي لها؛ أي: المفاضلة بين التضخم المدمق والبطاتلة ( السرت , 2008).

الانتقادات الموجهة لمنحنى فيليبس:

على الرغم من مصداقية النظرية العلمية التي تمتع بها منحنى فيليبس خلال فترة دراستاه, وبقيت على حالها حتى أواخر

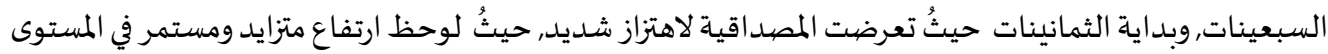
العام للأسعار في الوقت الذى ترتفع بشكل متزايد معدلات البطالة؛ مما شكل انتقادات شديدة لهذا المنحنى, وقصيوره على تفسير متزامن لمعدلات البطالة والتضخم معًا أو ما يسمى بالركود الاقتصادي (Stagflation) خلال فترة الركود

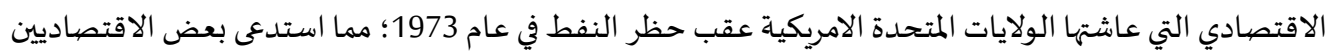
لإجراء تعديلات على فيليبس وسمى "منحنى فيليبس المعدل ", و هو شائع الاستخدام في وقتنا الحاضر و قد جذب انتباه

الكثير من صانعي السياسات الاقتصادية (Sobry,1996).

حيثُ برزت ظاهرة الركود التضخمي في مطلع السبعينات(القرن الماضي)لتزيد من الشكوك التي أثيرت حول عدم صحة منحنى فيليبس عندما بدأت الدول المتقدمة تعاني من ظاهرة تزامنت فيها معدلات بطالة عالية مصحوبة بمعدلات تضخم مرتفعة (الوزني , 1999 ). كما ظهر تفسير آخر مفاده أَنَّ العلاقة العكسية بين معدل التضخمر ومعددل البطالة علاقة مؤقتاة وليست ثابتة, ففي

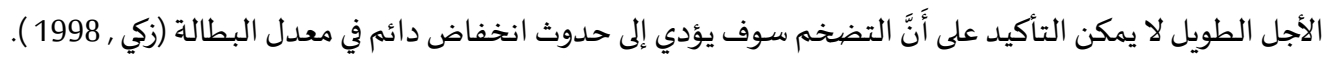
2. التحليل البياني لمنحنى "Philips Curve": الشكل الآتي ( 1) يوضح العلاقة العكسية بين معدل البطالة, ومعدل التضخم.

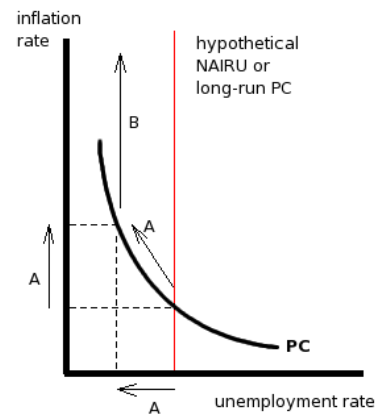

الشكل (1) يوضح العلاقة العكسية بين معدل البطالة ومعدل التضخم

نلاحظ من الشكل السابق وجود علاقة عكسية بين التضخم والبطالة والتي يعبر عنها منحنى فيليبس"Philips Curve"؛ أي: أَنَّ كل نقطة عليها تعني مستوى معين من البطالة, وما يقابله من التضخم. وعلى الحكومة أن تختار أي نقطة من التوليفات المختلفة الواقعة على المنحنى؛ لكي تضع السياسات المناسبة بشأن الاستقرار الاقتصادي, والتوظيف على مستوى الاقتصاد الوطني. لذا تم التوصل إلى وجود دالة متناقصة بين المؤشرين. يعني وجود علاقة تبادلية عكسية بين

معدل ارتفاع الاجر الاسمي, ومعدل البطالة (دانيال , 1992 ). 3. التحليل الرياضي لمنحنى فيليبس: تمت صياغة معادلة منحنى فيليبس كما يلي: يعبر معدل ارتفاع الأجور عنده بالشكل (Wto)هو أجر الفترة الحالية, (Wto) هو أجر الفترة السابقة. 


$$
w^{*}=\left(\frac{w_{t-w_{t o}}}{w_{t o}}\right)
$$

ولنجعل (u*) تمثل معدل البطالة الطبيعي, ومنه يمكن كتابة منحنى فيليبس على النحو الآتي:

$$
w^{*}=-e\left(u-u^{*}\right)
$$

$$
\begin{gathered}
\left(\frac{w_{t}-w_{t o}}{w_{t o}}\right)=-e\left(u-u^{*}\right) \\
w_{t}=w_{t o}\left(1-e\left(u-u^{*}\right)\right)
\end{gathered}
$$

لكي ترتفع الأجور فوق مستواها السابق, يجب على معدل البطالة أن ينخفض تحت معدله الطبيعي أي (u

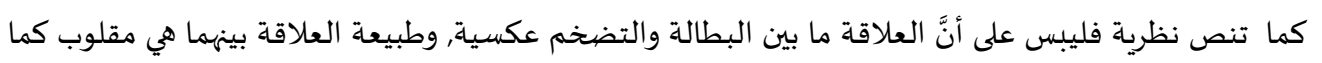

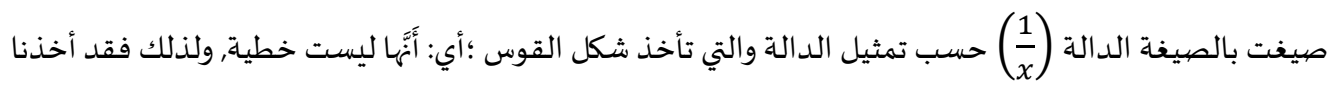
المتغير المستقل كدالة عكسية قبل بداية تقدير نموذج معادلة فيليبس، والتي تكون على الشكل الآتي:

$$
\begin{gathered}
Y=\alpha+\beta\left(\frac{1}{i n f}\right) \\
U=\alpha+\left(\frac{1}{i n f}\right) \\
\left(\frac{1}{i n f}\right)=I N F
\end{gathered}
$$$$
\text { بحيثُ يكون لدينا }
$$

$$
U=\alpha+\beta I N F+e
$$

\section{ب. تطورمعدلات البطالة والتضخم في مناطق السلطة الوطنية الفلسطينية:}

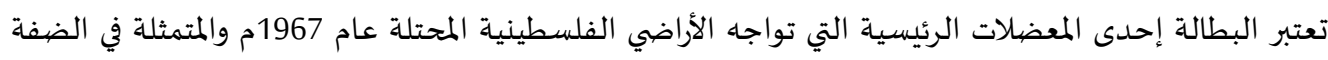

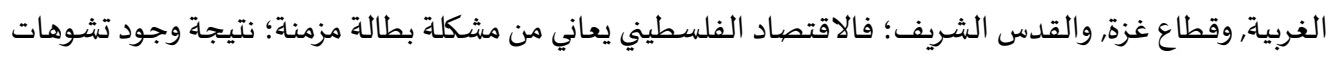

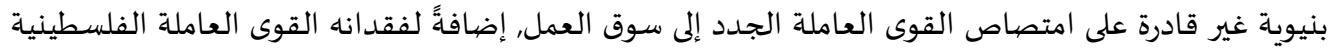

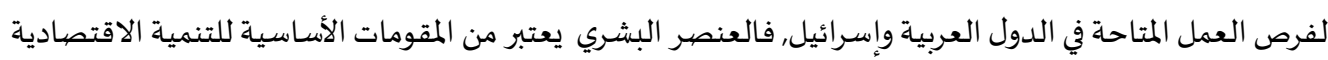

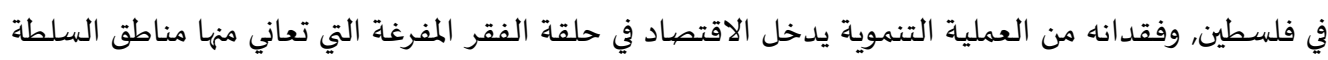
الوطنية الفلسطينية حالياً.

تعتبر أزمة التشغيل في مناطق السلطة الوطنية الفلسطينية, أزمة بنيوية في تركيبة الاقتصاد الفلسطيني؛ لاعتماده

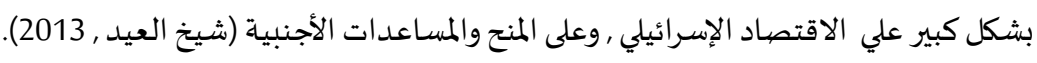

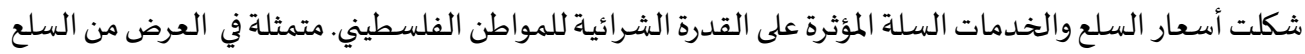

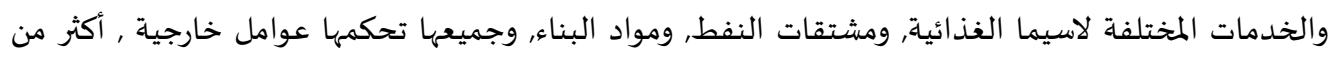
العوامل الداخلية؛ يعزى ذلك إلى عدة اعتبارات أهمها: 1. التفات أسعار السلع دولياً. 2. التغير في أسعار العملات الأجنبية لاسيما الدولار الأمريكي.

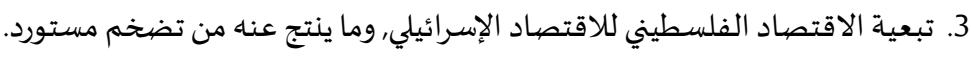


4. تذبذب أسعار الشيكل الإسرائيلي (العملة المتداولة في السوق الفلسطيني) مقابل العملات الأجنبية. 5. غياب عملة فلسطينية للتداول في السوق الفلسطيني بسبب رفض الاحتلال الإسرائيلي.

جدول (1) معدلات البطالة والتضخم في مناطق السلطة الوطنية الفلسطينية(1997-2019)

\begin{tabular}{|c|c|c|c|c|c|c|}
\hline \multicolumn{2}{|c|}{ قطاع غزة (\%) } & \multicolumn{2}{|c|}{ الضفة الغربية (\%) } & \multicolumn{2}{|c|}{ مناطق السلطة (\%) } & \multirow[t]{2}{*}{ متوسط الفترة } \\
\hline التضخم & البطالة & التضخم & البطالة & التضخم & البطالة & \\
\hline 3.30 & 28.6 & 0.39 & 18.52 & 4.1 & 21.5 & 2007-1997 \\
\hline 1.94 & 41 & 0.25 & 17.91 & 2.4 & 26.21 & 2019-2008 \\
\hline
\end{tabular}

البيانات تم احتساهها من قبل الباحث بناء على بيانات الجهاز المركزي للإحصاء الفلسطيني.

المرحلة الأولى :تطور معدلات البطالة والتضخم للفترة (1997-2007)

1. 1 - تطورمعدلات البطالة:

تذبذب معدلات البطالة في مناطق السلطة الوطنية الفلسطينية من فترة إلى أخرى وفق جدول رقم (1) حتى بلغ معدلها العام (21.5\%) خلال الفترة, وانعكس ذلك جلياً في معدلات البطالة في الضفة الغربية, وقطاع غزة؛ فكانت (18.5\%),(28.6\%) على التوالي؛ يعزى ذلك إلى عدوانية الإجراءات الإسرائيلية التي اتخذت عند اندلاع انتفاضة الأقصى في الريع الأخير من عام 2000م, والمتمثلة في تقييد دخول المواد الخام إلى المشاريع الفلسطينية المختلفة ,منع دخول العمال الفلسطينيين إلى عملهم في إسرائيل, وإغراق الأسـواق الفلسطينية بالمنتوجات الإسـرائيلية الجاهزة للاستهلاك الآدمي, إلى جانب تذبذب أسعار الشيكل الإسرائيلي(العملة المتداولة محلياً) مقابل الدولار الأمريكي, وتقطيع أوصال محافظات قطاع غزة عن بعضها ببعض, وإغلاق المعابر البرية, والجوية بين الفينة والأخرى, إضافة إلى عدم السماح لدخول الصيادين إلى البحر مسافات طويلة تحت حجج أمنية واهية. وزاد الاحتلال من قبضته الحديدية على مكونات الاقتصاد الفلسطيني؛ مما أدى إلى تناقص تدريجي (GDP)مع مرور الزمن, وأدى إلى تفاقم معدلات البطالة, واشتدت الأزمة الاقتصادية, وبلغت ذروتها في منتصف عام 2007م عند حدوث انقسام فلسطيني - فلسطيني, وتشكيل حكومتين: إحداهما في الضفة الغربية, والأخرى في قطاع غزة. والبيانات تم احتسابها من قبل الباحث بناء على بيانات الجهاز المركزي للإحصاء الفلسطيني.

2. تطور معدلات التضخم: نلاحظ من جدول (1) أَنَّ هناك ارتفاعُ في معدلات التضخم في مناطق السلطة الوطنية الفلسطينية حيثُ بلغ متوسطها العام (4.1\%) خلال الفترة ؛ يعزى ذلك إلى ضعف الاستثمارات الداخلية, والخارجية, وتزايد حجم الضرائب على السلع والخدمات لاسيما مشتقات النفط ؛ مما انعكس ذلك جلياً على مناطق السلطة الوطنية الفلسطينية كل على حدة حيثُ بلغت معدلات التضخم (0.39\%) في الضفة الغربية, (3.30\%) في قطاع غزة؛ يعزى ذلك إلى وجود تضخم مستورد من

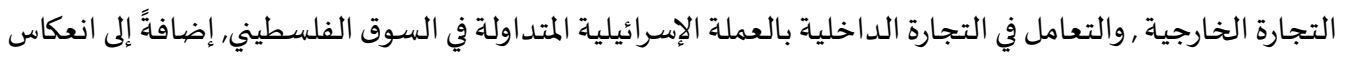
التضخم في إسرائيل على التضخم في شطري مناطق السلطة الوطنية الفلسطينية, وتذبذب أسعار العملات المتداولة في السوق الفلسطيني, والتي تتمثل في (الشيكل الإسرائيلي, والدينار الأردني, والدولار الأمريكي) في ظل غياب عملة فلسطينية للتداول في السوق الفلسطيني.

المرحلة الثانية: تطور معدلات البطالة والتضخم للفترة (2008-19) 1. 1. تطور معدلات البطالة:

نلاحظ من الجدول رقم (1) أَنَّ معدلات البطالة قد ارتفعت على مدار الفترة حيثُ ارتفع متوسطها العام من (21.5\%) إلى إلى (26.2\%)؛ أي: بزيادة ملحوظة بمعدل (4.7\%), وقد انعكس ذلك جلياً على معدلات البطالة في محافظات قطاع غزة إذ ارتفعت معدلاتها من (28.6\%) إلى (41\%)؛ أي: بزيادة قدرها (12.4\%)؛ يعزى ذلك إلى الانقسام الفلسطيني الذي حدث 
في منتصف عام 2007م, ومازال مستمرًا دون الوصول إلى وحدة وطنية فلسطينية رغم جولات المفاوضات المتكررة بين الفلسطينيين. وقد أثر الانقسام الفلسطيني سياسياً, واقتصادياً على المجتمع الفلسطيني بالسلب على كافة الأصعدة

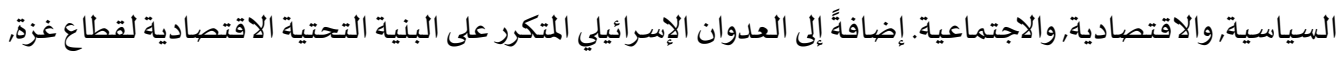

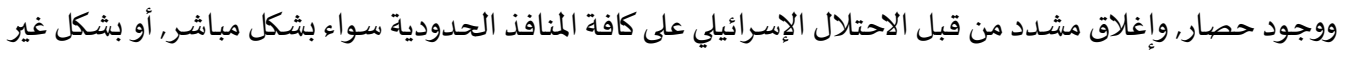

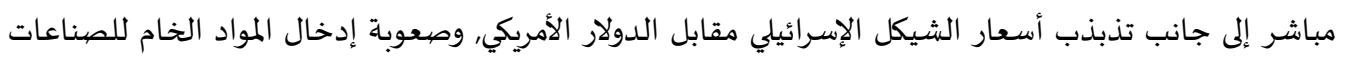
المحلية, ولقطاع الإنشاءات والزراعاة, وعدم السماح للعمال الفلسطينيين بالعمل داخل قطاع غزة. أما في الضفة الغربية فقد انخفضت معدلات البطالة من (18.5\%) إلى (17.9\%)؛ أي: بمعدل انخفاض(0.06\%), وهي ذسبة ضئيلة جداً؛ يعزى ذلك إلى تشغيل (120) ألف عامل في داخل إسرائيل, إلى جانب فتح المعابر الحدودية بشكل دائم, وتسهيل إدخال المواد الخام, إضيافةً إلى وجود حواجز عسكرية احتلالية إسرائيلية بين محافظات الضفية الغربية, وتهويد الأراضي الفلسطينية, وتجريف الأراضي المزروعة ,ونقل مركزية قرار المؤسسات العامة من قطاع غزة إلى الضفة الغربية أثر حدوث الانقسام الفلسطيني.

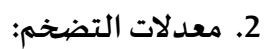

نلاحظ وفق الجدول(1) وجود انخفاض شديد في المعدل العام للتضخم لمتوسط الفترة (2008-2019) في مناطق السلطة الوطنية الفلسطينية حيثُ بلغت (2.4\%)؛أي: انخفضت بمقدار (1.7\%) مقارنة لمتوسط الفترة (1997-

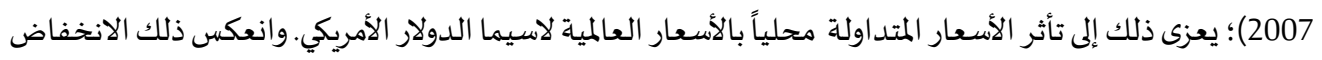
على الضفة الغربية إذ انخفضت من (0.39\%) لمتوسط الفترة (1997-2007) إلى (0.25\%) لمتوسط الفترة (20082019)؛ أي:انخفضت بمقدار (0.14\%), بينما في قطاع غزة فقد انخفضت من (3.30\%) لمتوسط الفترة (1997-2007) إلى (1.94\%) لمتوسط الفترة (2008-2019)؛ أي: انخفضت بمقدار (1.36\%)؛ يعود ذلك إلى تهرب الاحتلال الإسرائيلي من استحقاقات اتفاق باريس الاقتصادي الناظم للعلاقة الاقتصادية بين منظمة التحرير الفلسطينية, والاحتلال الإسرائيلي في عام 1994, والتي تنص على ضرورة خفض الاحتلال الاسرائيل لمشتقات النفط في حالة انخفاض أسعار البترول عالمياً إلى (30\%) في مناطق السلطة الوطنية الفلسطينية إلا أنَّ الاحتلال الإسرائيلي اكتفى بتخفيضهيا إلى (10\%) في مناطق السلطة الوطنية الفلسطينية. علماً بأنَّ عوائد مشتقات النفط وضرائهها تعتبر من أهم الموارد المالية للسلطة الوطنية الفلسطينية, والعمود الفقري لتحديد مستوى المعيشة في مناطق السلطة الوطنية الفلسطينية, وكذلك قيام سلطات الاحتلال الإسرائيلي باحتجاز أموال المقاصة بين الفنية , والأخرى التي تجبيها سلطات الاحتلال

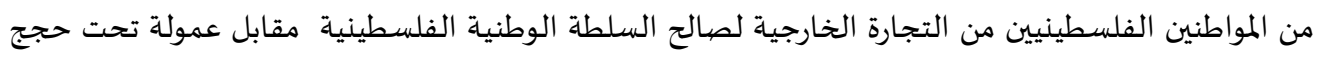
أمنية واهية.

إجراءات الدراسة:

تتمثل إجراءات الدراسة الحالية وطريقتها في الآتي: منهج الدراسة :

المنهج الاستنباطي: تعتمد الدراسة على المنهج الوصفي, والمتمثل في الإطار النظري لعلاقة البطالة والتضخم في مناطق السلطة الوطنية الفلسطينية, وفي شطري المناطق الفلسطينية:(الضفة الغربية, وقطاع غزة) كل على حدة. المنهج الاستقر ائي: يستخدم الأدوات الإحصائية من أجل تحليل البيانات والمعلومات المتعلقة بمعدلات البطالة,

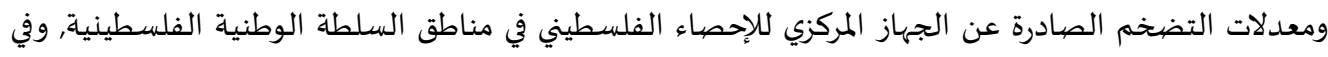
شطري المناطق الفلسطينية:(الضفة الغربية, وقطاع غزة) كل على حدة.

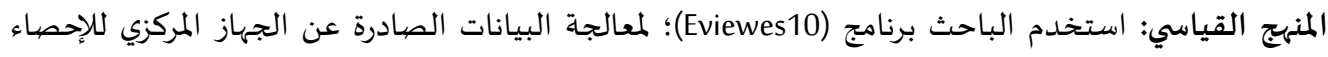

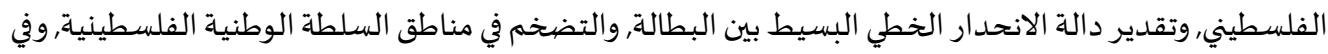

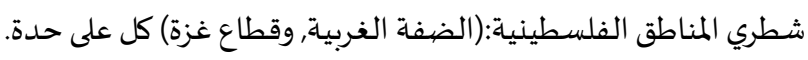




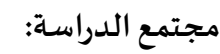

اقتصياد الضفة الغربية وقطاع غزة .

عينة الدراسـة: - n

مسح شامل للبيانات الاقتصادية السنوية الصادرة عن الجهاز المركزي للإحصياء الفلسطيني (2019) ), البطالة

والتضخم ).

أداة الدراسـة:

سلسلة زمنية لظاهرتي: البطالة والتضخم للفترة(2019/1997م).

الإطار التطبيقي للدراسـة:

تنص نظرية فليبس على أَنَّ العلاقة ما بين البطالة والتضخم عكسية, وطبيعة العلاقة بينهما هي مقلوب الدالة ( حيثُ إنَّ النموذج غير خطي بسيط, وبسبب المشاكل الإحصائية سنفترض أَنَّ النموذج خطي بسيط .

صبياغة النموذج القياسي :

تم صياغة النموذج القياسي ليعبر عن متغير التضخم, ومدى تأثيره في معدلات البطالة في الاقتصياد الفلسطيني عامة, وعلى اقتصاد الضفة الغربية, وقطاع غزة كل على حدة خلال الفترة الزمنية (1997-2019) حيثُ يعالج بيانات سلسلة زمنية سنوية صادرة عن الجهاز المركزي للإحصاء الفلسطيني تحوي على (23) مشاهدة وفق المعادلة الآتية:

$$
U_{t}=f\left(I N F_{t}\right)
$$

بناءً على المعادلة (8) السابقة أَنَّ هناك متغيراً تابعاً ( ويرمز إلى معدلات التضخم. و أخذ قيم المتغيرين التابع والمستقل كنسب مئوية.

تم استعمال الصيغة اللوغاريتمية لما لها أهمية بالغة في تقدير النماذج القياسية؛ كونها تعطي المرونات طويلة الأجل للمتغير المستقل (INF), وتأثيره على المتغير التابع (U)؛ وتقلل من تشتت البيانات , لاستقراريه السلسلة الزمنية للمتغيرين ( البطالة والتضخم), ولتحويل العلاقة غير خطية إلى علاقة خطية, كما تمكننا إلى استخدام طريقة المئقة المربعات الصغرى(OLS) العادية ؛ لتقدير معالم المعادلة. ولتصبح الدالة تمثل نموذج الانحدار البسيط التهيك آلتي :

$$
L N U_{t}=a+b_{0} L N I N F_{t}+e_{t}
$$

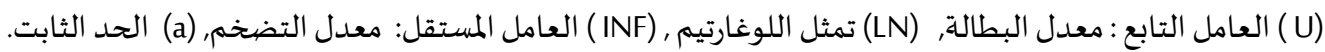
(e) المتغير العشوائي, (b) معامل خط الانحار لمعامل التضخم بالنسبة لمعدل البطالة.

أولاً: تقدير دالة الانحدار البسيط في مناطق السلطة الوطنية الفلسطينية:

1. تقدير النموذج للعلاقة بين معدلات التضخم والبطالة في مناطق السلطة الوطنية الفلسطينية

\begin{tabular}{|c|c|c|c|c|c|c|c|c|c|}
\hline \multirow[t]{2}{*}{ Variable } & \multirow[t]{2}{*}{ coefficient } & \multirow[t]{2}{*}{ Prob. } & \multirow[t]{2}{*}{ D.W } & \multirow[t]{2}{*}{$R^{2}$} & \multirow[t]{2}{*}{$\mathbf{F}$} & \multirow[t]{2}{*}{$R^{-2}$} & $\begin{array}{l}\text { Breusch- } \\
\text { Godfrey LM }\end{array}$ & \multicolumn{2}{|c|}{$\begin{array}{c}\text { Heteroscedasticity } \\
\text { Tests }\end{array}$} \\
\hline & & & & & & & Test: & $\mathrm{ARCH}$ & White \\
\hline
\end{tabular}
جدول (2) : يوضح العلاقة بين معدلات التضخم والبطالة في مناطق السلطة الوطنية الفلسطينية 


$\begin{array}{cccccccccc}C & 3.231 & 0.000 & 0.891 & 0.197 & 5.152 & 0.158 & 12.24 & 5.75 & 4.09 \\ \text { LNINF } & -0.104 & 0.033 & & & (0.033) & & & \end{array}$

يكون تقدير النموذج في مناطق السلطة الوطنية الفلسطينية كما يلي:

$$
L N U_{t}=3.231-0.104 L N I N F_{t}+e_{t}
$$

يتبين من نتائج التقدير الواردة في الجدول (2) النقاط الآتية:

النموذج مقبول اقتصادياً حيثُ إنَّ إشـارة معامل الانحدار سالبة منحنى فيليبس الذي يبين وجود العلاقة العكسية الدائمة بين معدل البطالة, ومعدل التضخم. يعني زيادة تغير التضخم بوحدة واحدة تؤدي إلى انخفاض البطالة بواقع (10.4\%) وحدة. تعتبر القدرة التفسيرية للنموذج ضعيفة بالنظر إلى قيمة (Adjusted R- Squared) معامل التحديد المعدل إذ يفسر بأَنَّ (15.8\%) من التغيرات الحاصلة في التضخم في مناطق السلطة الوطنية الفلسطينية سبيها ارتفاع معدل البطالة , في حين تعود (84.2\%) من التغيرات الحاصلة فياء تعود لأسباب أخرى.

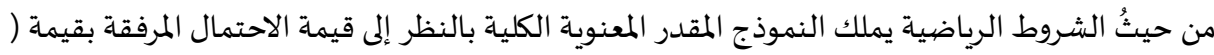
إحصائية فيشر Prob (F-statistic حيثُ بلغت 0.033 >0.05, ويملك المعنوية الجزئية بالنظر إلى الاحتمال

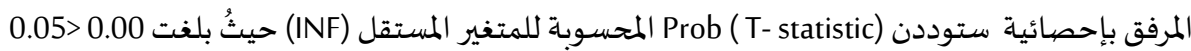
يمكن اعتبار الحد الثابت (c) دالاً إحصائياً, ومعنوياً غير مساو للصفر؛ لكون فرضية العدم معدومة (1)

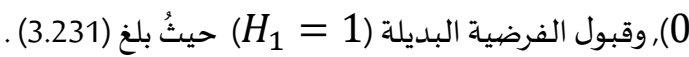
اختبار دربن واطسون(DW) : نجد أنَّ قيمة الارتباط الذاتي (P>0), وعليه نرفض فرضية العدم, ونقبل

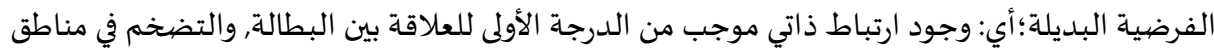

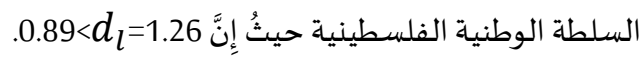
ذاّ هeusch-Godfrey Serial Correlation LM Test

$$
\text { ذاتي من الدرجة السابعة . }
$$

LM=12. 24<12.59 (LNINF $; 0.05 ; 6)$

:Heteroscedasticity Test: ARCH البسيط , وعليه نقبل فرضية العدم , حيثُ إنَّ : . LM= 5.75<5.99 (LNINF $\left.{ }^{2} ; 0.05 ; 2\right)$

Heteroskedasticity Test: White السلطة الوطنية الفلسطينية, وعلياء نقبل فرضية العدم ؛أي: بقي التوزيع الاحتمالي للمتغير العشوائي ثابتاً

$$
\text { لكل قيم التضخم في نموذج الانحدار الخطي البسيط, حيثُ إنَّ: }
$$

$\mathrm{LM}=4.09<5.99 \quad\left(\right.$ LNINF $\left.^{2} ; 0.05 ; 2\right)$

2. العلاقة السببية بين معدلات التضخم والبطالة في مناطق السلطة الوطنية الفلسطينية جدول رقم (3) يوضح العلاقة السببية بين معدلات التضخم والبطالة في مناطق السلطة الوطنية الفلسطينية

\begin{tabular}{lcccc}
\hline Null Hypothesis: & Lags & Obs & F-Statistic & Prob. \\
\hline LN INF does not Granger Cause LN U & 1 & 22 & 6.050 & 0.023 \\
LN U does not Granger Cause LN INF & & & 0.012 & 0.913 \\
LN INF does not Granger Cause LN U & 2 & 21 & 2.527 & 0.112 \\
& & & & \\
\hline
\end{tabular}


بين اختبار السببية (Granger) كما هو موضح في جدول (3) وجود أثر بين متغير التضخم, وبين متغير البطالة

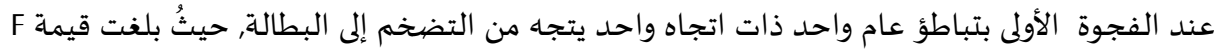

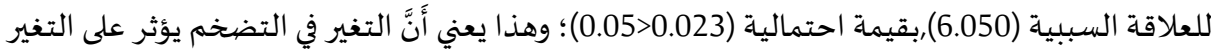

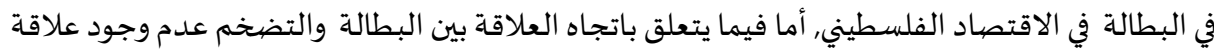
سببية بينهما حيثُ بلغت قيمة F (0.012), بقيمة احتمالية (0.913> 0.05)؛ وهذا يعني أَنَّ التغير في البطالة

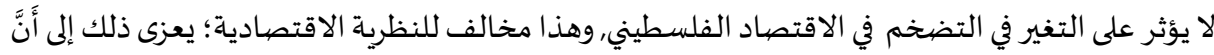
التضخم في الاقتصاد الفلسطيني هو تضخم مستورد, كونه اقتصاداً خدمياً وليس إنتاجياً, واستهلاكياً يعتمد على الواردات بدرجة كبيرة. لذا لا تؤثر البطالة على التضخم.

بين اختبار السببية (Granger) كما هو موضح في جدول (3) عدم وجود أثر بين متغير التضخم, وبين متغير

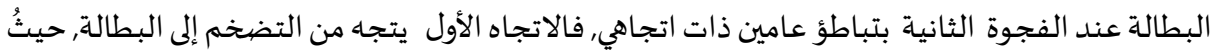

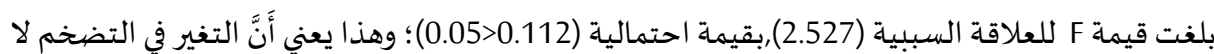
يؤثر على التغير في البطالة في الاقتصاد الفلسطيني, أما فيما يتعلق باتجاه العلاقة بين البطالة والتضخم؛ التهاء

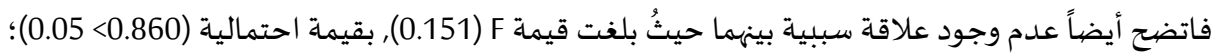

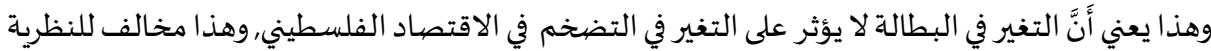
الاقتصادية؛؛ يعزى ذلك إلى أنَّ التضخم في الاقتصاد الفلسطيني هو تضخم مستورد, إضيافةً لغياب السياسـة النقدية الفلسطينية؛ ولغياب العملة الفلسطينية, وكونها يعتمد على الواردات بدرجة كبيرة, وأنَّ هناك ثلاث عملات متداولة في الاقتصاد الفلسطيني:(الدولار الأمريكي, والشيكل الإسرائيلي, والدينار الأردني). إضيافةً

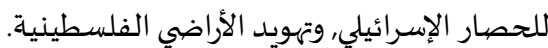

ثانياً: تقديردالة الانحدار البسيط في الضفة الغربية:

1. تقدير النموذج للعلاقة بين معدلات التضخم والبطالة في مناطق الضفة الغربية:

جدول رقم (4) يوضح العلاقة بين معدلات التضخم والبطالة في مناطق الضفة الغربية

\begin{tabular}{|c|c|c|c|c|c|c|c|c|c|}
\hline \multirow[t]{2}{*}{ Variable } & \multirow[t]{2}{*}{ Coeff. } & \multirow[t]{2}{*}{ Prob. } & \multirow[t]{2}{*}{ D.W } & \multirow[t]{2}{*}{$R^{2}$} & \multirow[t]{2}{*}{$F$} & \multirow[t]{2}{*}{$R^{-2}$} & \multirow{2}{*}{$\begin{array}{l}\text { Breusch- } \\
\text { Godfrey LM } \\
\text { Test }\end{array}$} & \multicolumn{2}{|c|}{$\begin{array}{c}\text { Heteroscedasticity } \\
\text { Tests }\end{array}$} \\
\hline & & & & & & & & $\mathrm{ARCH}$ & White \\
\hline $\begin{array}{c}C \\
\angle N I N F\end{array}$ & $\begin{array}{r}2.884 \\
-0.010\end{array}$ & $\begin{array}{l}0.000 \\
0.739\end{array}$ & 0.658 & 0.005 & $\begin{array}{c}0.113 \\
(0.739)\end{array}$ & -0.041 & 17.28 & 11.459 & 4.197 \\
\hline
\end{tabular}

المصدر : اعداد الباحث اعتماداً على مخرجات برنامج (10) Eveiwes

تم تقدير النموذج في الضفة الغربية على النحو التالي:

$$
L N U_{t}=2.884-0.010 L N I N F_{t}+e_{t}
$$

تبين من نتائج التقدير الواردة في الجدول (4) النقاط الآتية:

النموذج مقبول اقتصادياً حيثُ إِنَّ إشـارة معامل الانحدار سالبة البهار النظرية الاقتصادية التي تبين وجود العلاقة العكسية الدائمة بين معدل البطالة , ومعدل التضخم وفق مُ إنق منحنى فيليبس . يعني زيادة تغير التضخم بوحدة واحدة تؤدي إلى انخفاض البطالة بواقع (1\%) وحدة. 
تعتبر القدرة التفسيرية للنموذج ضعيفة جداً بالنظر إلى قيمة (Adjusted R- Squared) معامل التحديد المعدل إذ يفسر بأَنَّ (-4\%) من التغيرات الحاصلة في التضخم في الضفية الغربية سببها ارتفاع معدل البطالة في حين تعود (104\%) من التغيرات الحاصلة فياء لأسباب أخرى, وهذا يدلل على أنَّهُ لا توجد أي علاقة بينهما إطلاقاً.

من حيثُ الشروط الرياضية لا يملك النموذج المقدر المعنوية الكلية بالنظر إلى قيمة الاحتمال المرفقة بقيمة احصيائية فيشر (F-statistic)Prob حيثُ بلغت 0.05 >0.739, ولا يملك المعنوية الجزئية بالنظر إلى الاحتمال

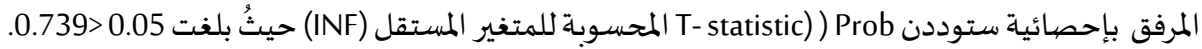

يمكن اعتبار الحد الثابت(c) دالاً إحصائياً, ومعنوياً غير مساو للصفر؛ لكون فرضية العدم معدومة

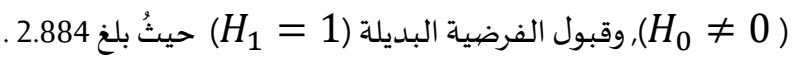

اختبار دربن واطسون(W.D) : نجد أَنَّ قيمة الارتباط الذاتي (P>0), وعليه نرفض فرضية العدم , ونقبل

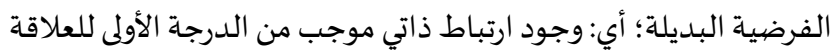
بين البطالة والتضخم في الضفة الغربية حيثُ 1.26=d > 0.658 Breusch-Godfrey Serial Correlation LM Test: تم تعديل مشكلة الارتباط المتسلسل بإدراج نموذج انحدار ذاتي من الدرجة العاشرة $L M=17.28<18.31$ $\left(L N I N F^{10} ; 0.05 ; 10\right)$

:Heteroscedasticity Test: ARCH نجد أنَّ التباين الشرطي للأخطاء ثابت في نموذج الانحدار الخطي البسيط, وعلياء نقبل فرضية العدم. $\mathrm{LM}=11.459<15.51 \quad$ ( LNINF $\left.^{8} ; 0.05 ; 8\right)$ :Heteroscedasticity Test: White نجد تحقق فرضية تجانس تباين الأخطاء لدى التضخم في الضفة الغربية, وعليه نقبل فرضية العدم ؛ أي: بقي التوزيع

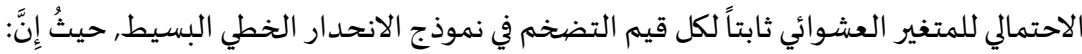
$\mathrm{LM}=4.197<5.99 \quad\left(\operatorname{LNINF}^{2} ; 0.05 ; 2\right)$

2. العلاقة السببية بين معدلات التضخم والبطالة في الضفة الغربية :

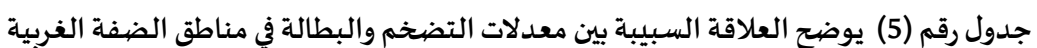

\begin{tabular}{|c|c|c|c|c|}
\hline Null Hypothesis: & Lags & Obs & F-Statistic & Prob. \\
\hline LN INF does not Granger Cause LN U & \multirow{2}{*}{1} & \multirow{2}{*}{22} & 0.113 & 0.740 \\
\hline LN U does not Granger Cause LN INF & & & 0.001 & 0.971 \\
\hline LN INF does not Granger Cause LN U & \multirow{2}{*}{2} & \multirow{2}{*}{21} & 1.638 & 0.225 \\
\hline LN U does not Granger Cause LN INF & & & 0.003 & 0.996 \\
\hline
\end{tabular}

Eveiwes (10) المصدر : اعداد الباحث اعتماداً على مخرجات برنامج

بين اختبار السببية (Granger) كما هو موضح في جدول (5) عدم وجود أثر بين متغير التضخم, وبين متغير

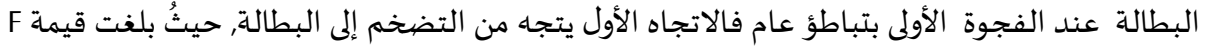

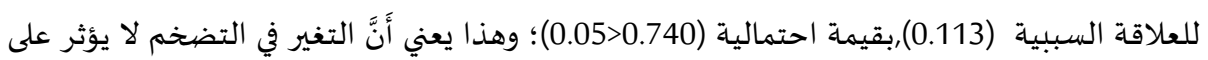


التغير في البطالة في اقتصاد الضفة الغربية , أما الاتجاه الثاني فيما يتعلق باتجاه العلاقة بين البطالة والتضخم عدم وجود علاقة سببية بينهما حيثُ بلغت قيمة F (0.001), بقيمة احتمالية (0.971> 0.05)؛

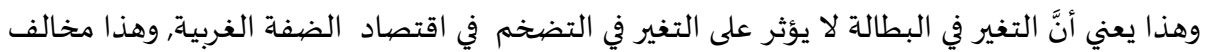
للنظرية الاقتصادية؛ يعزى ذلك إلى أنَّ التضخم في اقتصاد الضفة الغربية هو تضخم مستورد, كونها

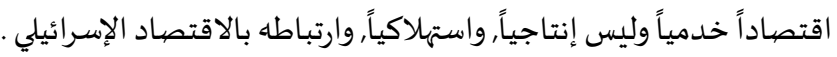

بين اختبار السببية (Granger) كما هو موضح في جدول (5) عدم وجود أثر بين متغير التضخم, وبين متغير

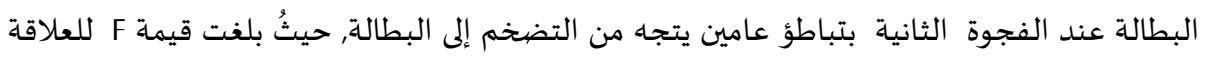

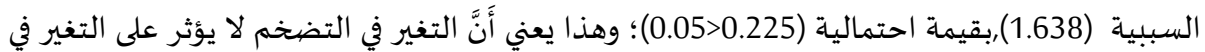
البطالة في اقتصاد الضفة الغربية , أما فيما يتعلق باتجاه العلاقة بين البطالة والتضخم عدم وجود علاقة سببية بينهما حيثُ بلغت قيمة F F (0.003), بقيمة احتمالية (0.996> 0.05)؛ وهذا يعني أَنَّ التغير في البطالة لا يؤثر على التغير في التضخم في اقتصاد الضفة الغربية , وهذا مخالف للنظرية الاقتصادية؛ يعزى ذلك إلى أَنَّ التضخم في الاقتصاد الفلسطيني عامة هو تضخم مستورد, ويرجع ذلك إلى وجود متغيرات أخرى تسبب في معدلات التغير في البطالة.

ثالثاً: تقديردالة الانحدار البسيط في قطاع غزة:

تقدير النموذج للعلاقة بين معدلات التضخم والبطالة في مناطق قطاع غزة: .1 جدول رقم (6) يوضح العلاقة بين معدلات البطالة والتضخم في مناطق قطاع غزة

\begin{tabular}{|c|c|c|c|c|c|c|c|c|c|}
\hline \multirow[t]{2}{*}{ Variable } & \multirow[t]{2}{*}{ Coeff. } & \multirow[t]{2}{*}{ Prob. } & \multirow[t]{2}{*}{ D.W } & \multirow[t]{2}{*}{$R^{2}$} & \multirow[t]{2}{*}{$F$} & \multirow[t]{2}{*}{$R^{-2}$} & \multirow{2}{*}{$\begin{array}{l}\text { Breusch- } \\
\text { Godfrey } \\
\text { LM Test: }\end{array}$} & \multicolumn{2}{|c|}{$\begin{array}{c}\text { Heteroscedasticity } \\
\text { Tests }\end{array}$} \\
\hline & & & & & & & & $\mathrm{ARCH}$ & White \\
\hline C & 3.577 & 0.000 & \multirow{2}{*}{0.937} & \multirow{2}{*}{0.135} & 3.303 & \multirow{2}{*}{0.094} & \multirow{2}{*}{7.25} & \multirow{2}{*}{3.056} & \multirow{2}{*}{1.355} \\
\hline$\angle N I N F$ & -0.102 & 0.0834 & & & $(0.083)$ & & & & \\
\hline
\end{tabular}

تم تقدير النموذج للعلاقة بين معدلات التضخم والبطالة في قطاع غزة على النحو التهات التالي :

$$
L N U_{t}=3.577-0.102 \operatorname{LNINF}_{t}+e_{t}
$$

تبين من نتائج التقدير الواردة في الجدول (7) النقاط الآتية:

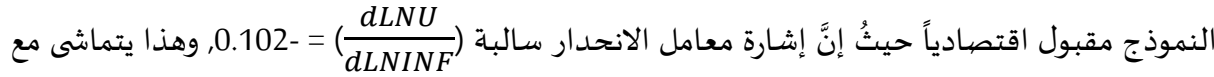

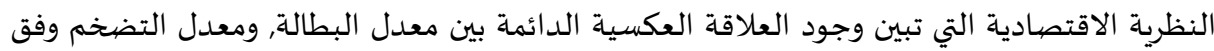
منحنى فيليبس. يعني زيادة تغير التضخم بوحدة واحدة تؤدي إلى انخفاض البطالة بواقع (10.2\%) وحدة.

تعتبر القدرة التفسيرية للنموذج ضعيفة بالنظر إلى قيمة (Adjusted R- Squared) معامل التحديد المعدل إإذ يُفسر بأنَّ (9.4\%) من التغيرات الحاصلة في التضخم في مناطق قطاع غزة سببها ارتفاع معدل البطالة , في حين تعود (90.6\%) من التغيرات الحاصلة فياه تعود لأسباب أخرى.

• من حيثُ الشروط الرياضية لا يملك النموذج المقدر المعنوية الكلية بالنظر إلى قيمة الاحتمال المرفقة بقيمة إحصائية فيشر (F-statistic)Prob حيثُ بلغت 0.05 >0.08, لكناه يملك المعنوية الجزئية بالنظر إلى الاحتمال المرفق بإحصيائية ستوددن T- statistic Prob المحسوبة للمتغير المستقل (INF) حيثُ بلغت 0.05 >0.00. 
• يمكن اعتبار الحد الثابت(c) دالاً إحصائياً, ومعنوياً غير مساو للصفر ؛ لكون فرضية العدم معدومة(

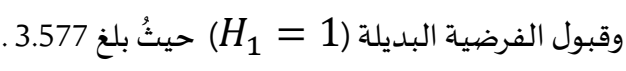

اختبار دربن واطسون : نجد أنَّ قيمة الارتباط الذاتي (P>0), وعليه نرفض فرضية العدم , ونقبل الفرضية البراية

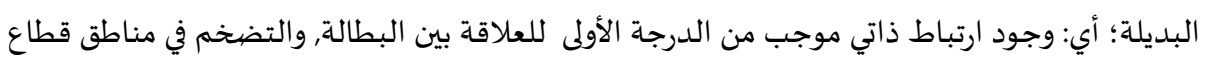

$$
\text { غزة حيثُ إِنَّ } 1.26 \text { أبل }
$$

Breusch-Godfrey Serial Correlation LM Test:

تم تعديل مشكلة الارتباط المتسلسل بإدراج نموذج انحدار ذاتي من الدرجة السادسة.

$$
\mathrm{LM}=7.25<7.81 \quad\left(\operatorname{LNINF}^{3} ; 0.05 ; 3\right)
$$

:Heteroscedasticity Test: ARCH

نجد أنَّ التباين الشرطي للأخطاء ثابت في نموذج الانحدار الخطي البسيط ,وعليه نقبل فرضية العدم , حيثُ إِنَّ :

$$
\text { 3.056< } \mathrm{LM}=3.84 \quad\left(\operatorname{LNINF}^{1} ; 0.05 ; 1\right)
$$

:Heteroscedasticity Test: White

نجد تحقق فرضية تجانس تباين الأخطاء لدى التضخم في مناطق السلطة الوطنية الفلسطينية, وعليه نقبل فرضية

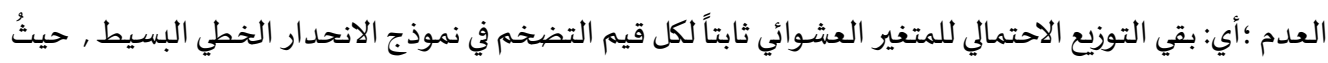

$$
1.355<\mathrm{LM}=5.99 \quad\left(\operatorname{LNINF}^{2} ; 0.05 ; 2\right)
$$

\begin{tabular}{|c|c|c|c|c|}
\hline Null Hypothesis: & lags & Obs & F-Statistic & Prob. \\
\hline LN INF does not Granger Cause LN U & \multirow{2}{*}{1} & \multirow{2}{*}{22} & 6.4333 & 0.0201 \\
\hline LNU does not Granger Cause LN INF & & & 1.6709 & 0.2116 \\
\hline LN INF does not Granger Cause LN U & \multirow{2}{*}{2} & \multirow{2}{*}{21} & 2.4463 & 0.1183 \\
\hline LN U does not Granger Cause LN INF & & & 0.4300 & 0.6578 \\
\hline
\end{tabular}

3. العلاقة السببية بين معدلات التضخم ومعدلات البطالة في قطاع غزة : جدول رقم (7) يوضح العلاقة السببية بين معدلات التضخم ومعدلات البطالة في في قطات البطاع غزة.

Eviews 10 اعداد الباحث اعتمادا على مخرجات برنامج

بين اختبار السببية (Granger) كما هو موضح في جدول (7) وجود أثر بين متغير التضخم, وبين متغير البطالة

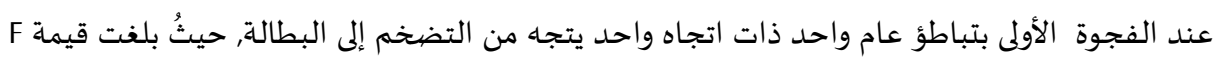

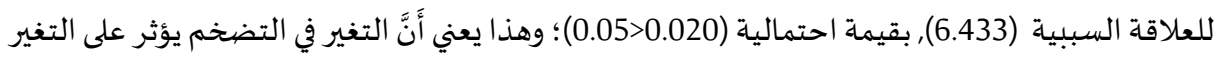

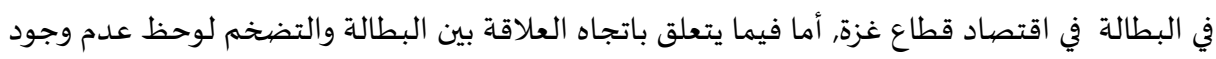

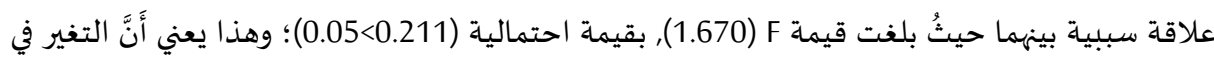

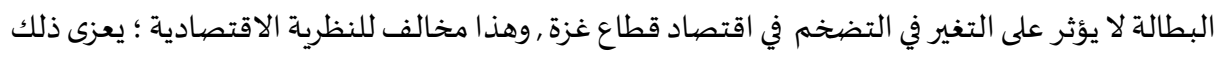

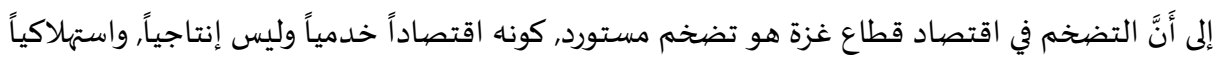

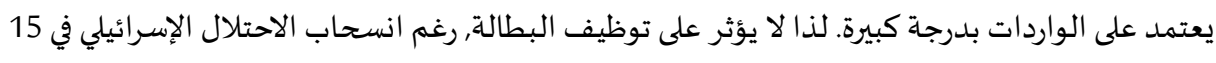

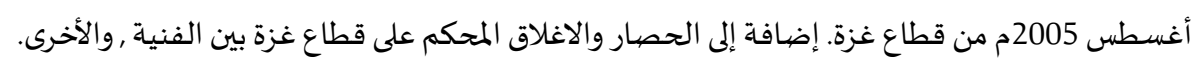




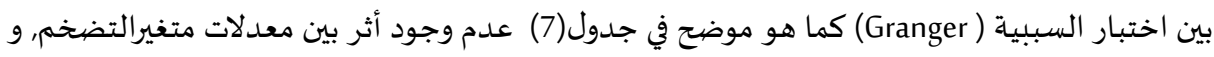

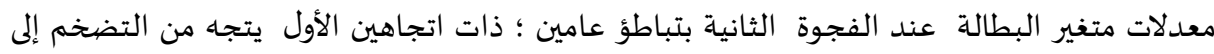

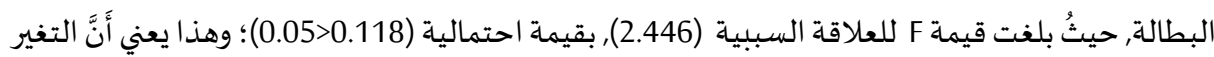

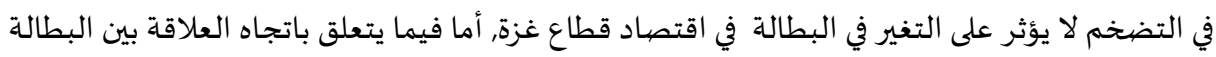

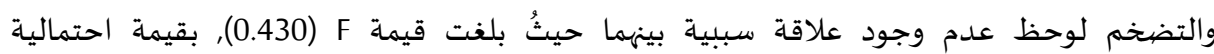

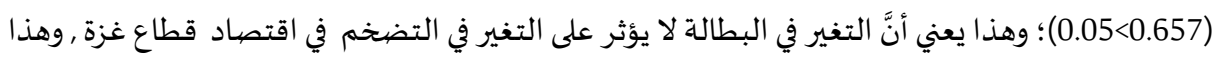

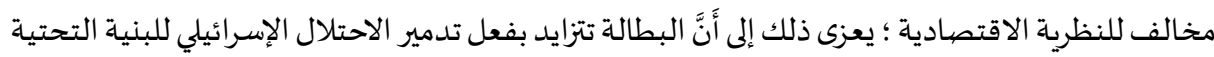

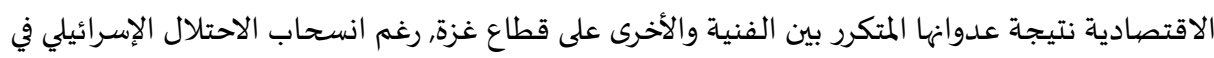

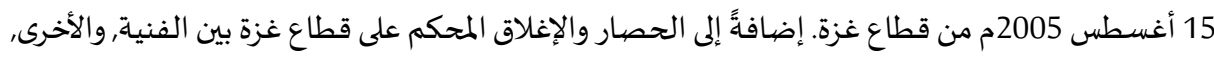
ومنح العمال الفلسطينيين من العمل داخل إسرائيل .

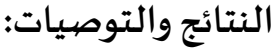

بعد الانتهاء من دراسة البحث الموسوم بـ :" العلاقة بين معدل التضخم, ومعدل البطالة في مناطق السلطة الوطنية

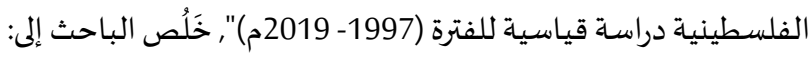
أولاًا النتائج: 1. يمكن تطبيق منحنى فيليبس على الاقتصاد الفلسطيني عامة، وبشقيه الضفة الغربية, وقطاع غزة, حيث أظهرت

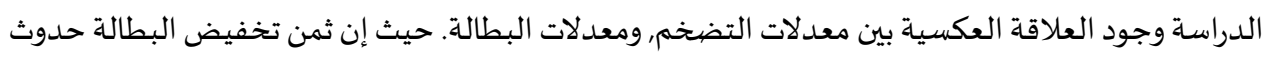
ارتفاع شديد في معدلات التضخم.

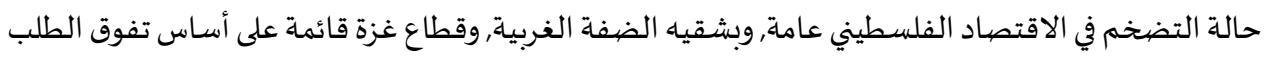

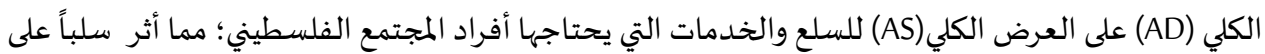
تركيبة الائتمان التجاري.

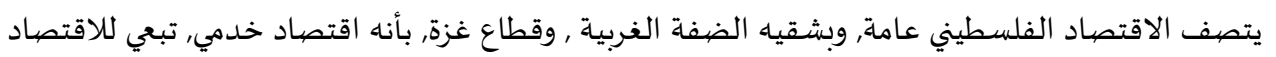

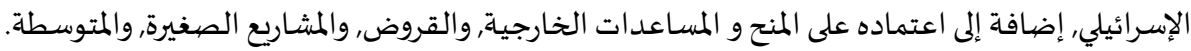

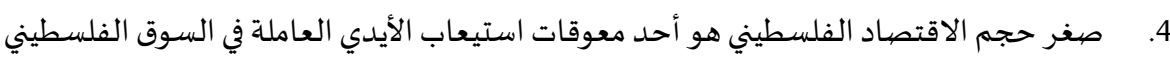

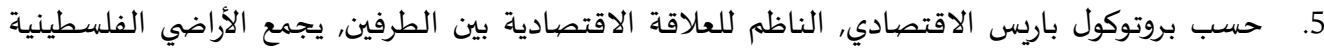

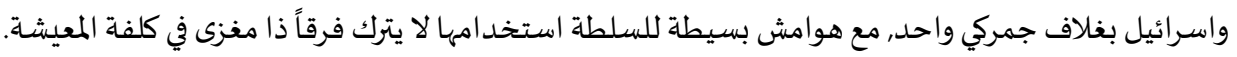

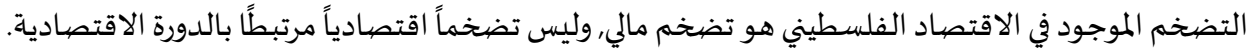

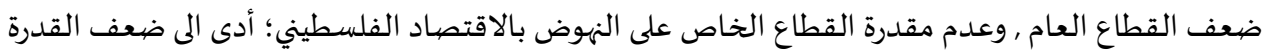
الاستيعابية للتوظيف.

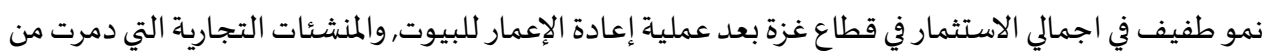

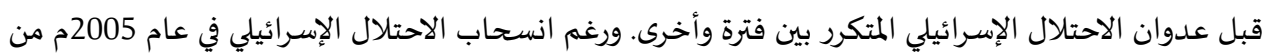

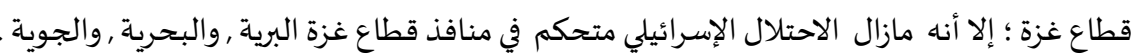

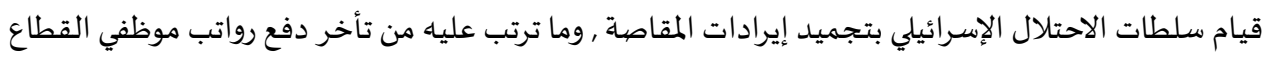

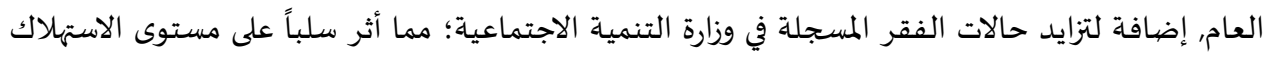
الخاص, وبالتالي على المستوى العام للأسعار .

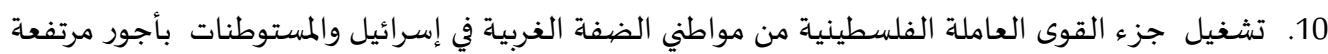

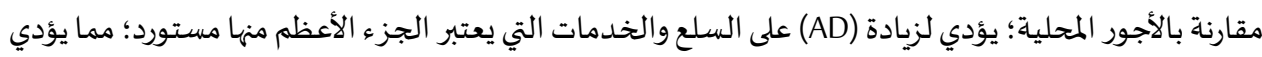

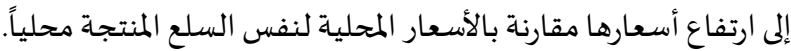

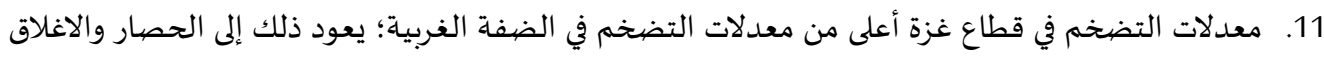

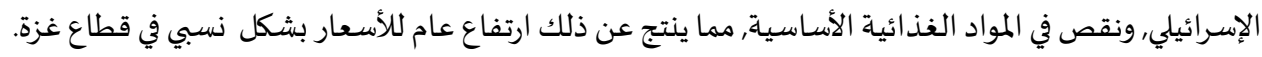


12. عدم وجود عملة وطنية فلسطينية لتستطيع سلطة النقد الفلسطينية السيطرة على التضخم وفق أدوات

السياسة النقدية .

ثانياً التوصيات:

رسم السياسات الاقتصادية الفلسطينية لابُدَّ أن تتم على أساس وحدة اقتصادية متكاملة للمنطقتين: (الضففة

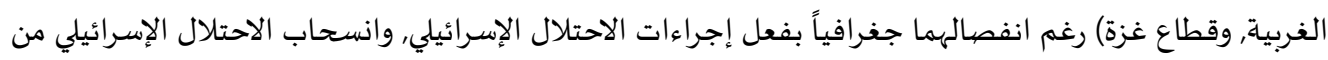

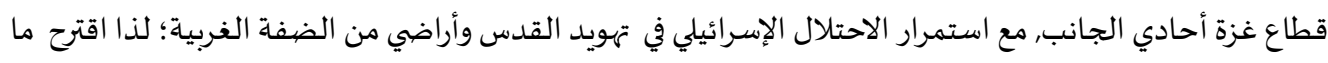

1. يجب مراجعة وتقييم السياسات الضريبية المعتمدة من قبل الحكومة على أساس حماية المستهلك الفلسطيني والأخذ بعين الاعتبار قدراته المالية واحتياجاته المعيشية.

2. العمل على توسيع التجارة الخارجية مع دول أخرى ذات مستويات أسعار, وتكاليف إنتاجية أقل نسبياً من أسعار السلع المستوردة من إسـرائيل.

3. ضرورة إصدار عملة فلسطينية ؛ لاستخدام السياسة النقدية في معالجة الظواهر الاقتصادية .

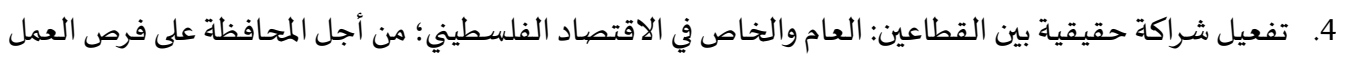
المتوفرة, وتوفير مشاريع استثمارية ذات كثافة عمالية .

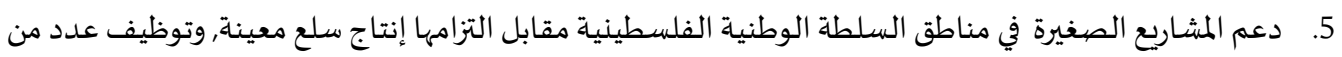
العمال لديها.

6. تشجيع المنتجون على زيادة الإنتاجية ؛ بغية تقليل الواردات ,وتشجيع الصادرات الفلسطينية , ومن ثم زيادة الطلب على الايدي العاملة الفلسطينية.

7. ضرورة انشاء مشاريع تنموية جديدة, او توسيع المشاريع التنموية القائمة؛؛ بهدف استيعاب الفائض من القوى

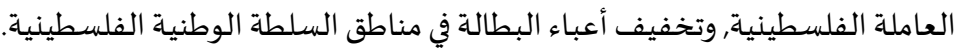

8. ضرورة وضع استراتيجية وتخطيط حقيقي , نحو استخدام التقنيات الحديثة ؛لتنمية القطاعات الإنتاجية بتكاليف

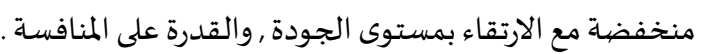




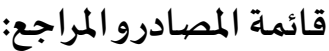

أولا: المراجع العربية

تومي, صالح (2009). مبادئ التحليل الاقتصادي الكلي(ط2) الجزائر : دار أسـامة للطباعة والنشر والتوزيع.

الجهاز المركزي, للإحصاء, الفلسطيني (2019). مسح القوى العاملة الفلسطينية . فلسطين: التقرير السنوي.

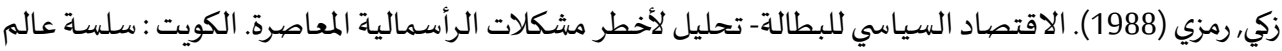

$$
\text { المعرفة. (رقم } 26 \text { ) . }
$$

$$
\text { زكي, رمزي (1986) ). التضخم المستورد ( ط1) القاهرة: دار المستقبل العربي للنشر. }
$$

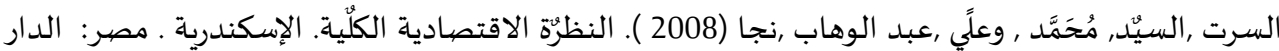

$$
\text { الجامعية للنشر. }
$$

شيخ العيد, جلال (2013) .تقدير دوال الطلب على القوى العاملة الفلسطينية في مناطق السلطة الوطنية الفلسطينية للفترة 1997-2011( أطروحة دكتوراة غير منشورة ), جامعة قاصدي مرباح , الجزائر.

عابد , نادية ,علي (2014). دراسـة قياسية لمنحنى فيليبس في العراق. مجلة جامعة البصرة للعلوم الاقتصيادية , 36

لعراف, فايزة روسعودي ,نجوى (2001) . دراسة قياسية لمنحنى فيليبس في الجزائر خلال الفترة2003 -2011 ـ بحث

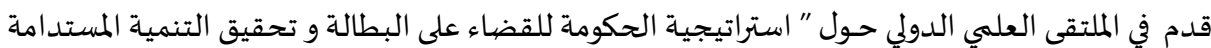
بكلية العلوم الاقتصادية والتجارية وعلوم التسيير , جامعة المسيلة, الجزائر. معروف ,هوشيار (2005). الاقتصاد الكلي (ط 1) . الأردن: دار صفاء للنشر والتوزيع.

موسوي, ضياء , مجيد (2001). اقتصاديات النقود والبنوك, الاسكندرية. مصر: مؤسسة شبعباب الجامعاة . ميلود روعيل, وهاني, مُحَمَّد (2018). العلاقة بين البطالة والتضخم دراسة قيدية قياسية لمنحنى فيليبس في الجزائر للفترة 2015-2000. مجلة آفاق للبحوث والدراسات بجامعة بويرة , ع2 304-314 .

الوزني ,خالد ,واصف, والرفاعي ,أحمد, حسين (1999). مبادئ الاقتصاد الكلي بين النظرية والتطبيق(ط 1 ) الأردن : دار وائل للنشر والطباعة . دانيال, أرنلد (1992) . تحليل الأزمات الاقتصادية للأمس واليوم (ط1) (الأمير شمس الدين, مترجم). لبنان: المؤسسة الجامعية للدراسات والنشر والتوزيع.

\section{ثانيا: المراجع العبربية المتوجمة}

Abed, N, A. (2014). A standard study of the Phillips curve in Iraq. Basra University Journal of Economic Sciences, 36 (9), 155-178.

Daniel, A. (1992). Analysis of Yesterday and Today's Economic Crises (1st ed.) (Shamsuddin, A. Trans.) Lebanon: University Foundation for Studies, Publishing and Distribution.

Tommy, S. (2009). Principles of Economic Analysis (2nd Edition) Algeria: Usama House for Printing, Publishing and Distribution.

Palestinian ,Central ,Bureau of Statistics, (2019). Palestinian Labor Force Survey. Palestine: Annual Report.

Learaf, F. \& Asaudi, N. (2001). A standard study of the Phillips curve in Algeria during the period 2003

2011. Paper presented at the International Scientific Forum on "The government's strategy to eradicate unemployment and achieve sustainable development at the Faculty of Economic, Business and Management Sciences", University of Messila, Algeria.

Marouf, H. (2005). Macroeconomics (1 ${ }^{\text {st }}$ ed.). Jordan: Safaa House for Publishing and Distribution. 
Miloud, W. \& Hani, M. (2018). The relationship between unemployment and inflation is a standard study of the Phillips curve in Algeria for the period 2000-2015. Prospects for Research and Studies at the University of Bouira, 2, 304-314.

Mousayi, D.M. (2001). Money and Banking Economics, Alexandria. Egypt: University Youth Foundation.

Sheikh ,Al-Eid, Jalal. (2013). Estimating the Demand Functions of the Palestinian Workforce in the Palestinian National Authority Areas for the Period 1997-2011 (Unpublished Doctoral dissertation), Qasidi Merbah Universit. , Algeria.

Al-Sirt, A, M. \& Ali, A, N. (2008). Macroeconomic theory. Alexandria. Egypt: University Publishing House.

Al-Wazni, K,W. \& Al-Rifai, A,H. (1999). Principles of Macroeconomics between Theory and Practice (1st Edition). Jordan: Wael Publishing and Printing House.

Zaki, R. (1988). The Political Economy of Unemployment - An analysis of the most serious problems of contemporary capitalism. Kuwait: The World of Knowledge Chain. (No. 26).

Zaki, R. (1986). Imported Inflation (1st ed.). Cairo: Dar Al-Mustaqbal Al-Arabi Publishing House.

\section{ثالثاً: المراجع الأجنبية}

Furuoka, F. \&, Munir, Q. (2014). Unemployment and Inflation in Malaysia Evidence from Error Correction Model, Malaysian Journal of Business and Economics, 1 (1), 35 -45.

Phillips, A. W. (1958). The Relation Between Unemployment and the Rate of - Change of Money Wage Rates in the United Kingdom1961-1957, Economica, 25 (100), 283-299.

Sargent, T. (1978). Rational Expectation, The Real Rate of Interest and The Natural Rate of Unemployment Brooking, Papers on Economic Activity, 2, 429-435.

Umoru, D. \& Anyiwe, M. A. (2013). Dynamics of inflation and unemployment in a Vector Error Correction Model, Research on Humanities and Social Sciences, 3(3), 20-29.

Verez, J. C. (1996). Elements of macroeconomic: an empirical and dynamic approach. Paris, France: Ellipses Editions. (In French). 